\title{
Health service literacy: complementary actor roles for transformative value co-creation
}

\author{
Fanet Davey \\ School of Marketing and International Business, Victoria University of Wellington, Wellington, New Zealand, and \\ Christian Grönroos \\ Hanken School of Economics, Helsinki, Finland
}

\begin{abstract}
Purpose - Although health-care features prominently in transformative service research, there is little to guide service providers on how to improve well-being and social change transformations. This paper aims to explore actor-level interactions in transformative services, proposing that actors' complementary health service literacy roles are fundamental to resource integration and joint value creation.

Design/methodology/approach - In-depth interviews with 46 primary health-care patients and 11 health-care service providers (HSPs) were conducted focusing on their subjective experiences of health literacy. An iterative hermeneutic approach was used to analyse the textual data linking it with existing theory.

Findings - Data analysis identified patients' and HSPs' health service literacy roles and corresponding role readiness dimensions. Four propositions are developed describing how these roles influence resource integration processes. Complementary service literacy roles enhance resource integration with outcomes of respect, trust, empowerment and loyalty. Competing service literacy roles lead to outcomes of discredit, frustration, resistance and exit through unsuccessful resource integration.

Originality/value - Health service literacy roles - linked to actor agency, institutional norms and service processes - provide a nuanced approach to understanding the tensions between patient empowerment trends and service professionals' desire for recognition of their expertise over patient care. Specifically, the authors extend Frow et al.'s (2016) list of co-creation practices with practices that complement actors' service literacy and role readiness. Based on a service perspective, the authors encourage transformative service researchers, service professionals and health service system designers, to recognize complementary health service literacy roles as an opportunity to support patients' resources and facilitate value co-creation.
\end{abstract}

Keywords Roles, Health services, Transformative, Health service literacy, Roles, Transformative services, Role readiness

Paper type Research paper

\section{Introduction}

The co-creation of well-being is a key focus of transformative services and transformative service research (TSR) (Rosenbaum, 2015). Increasingly, TSR is focusing on the health-care domain given the shared pursuit of increased wellbeing, both individually and societally (Sweeney et al., 2015). Although transformative service researchers are investigating network effects on value creation (Black and Gallan, 2015; Gallan et al., 2018) and the influence of institutional logics on the service relationship (Cheung and McColl-Kennedy, 2015), the role of the consumer (beyond participation) in well-being outcomes is underexplored. In particular, little research has explored the influence of consumers' and service providers' service literacy on advancing transformative services and transformative value co-creation. It is in this area where our research contributes, specifically in the interrelationships between complementary and competing health service literacy roles in transformative value co-creation.

The current issue and full text archive of this journal is available on Emerald Insight at: www.emeraldinsight.com/0887-6045.htm

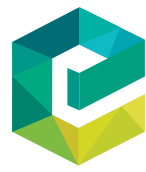

Journal of Services Marketing

33/6 (2019) 687-701

(C) Emerald Publishing Limited [ISSN 0887-6045]

[DOI 10.1108/JSM-09-2018-0272]
TSR shares many attributes with social marketing, based on common underlying goals of improving well-being for individuals and society (Anderson et al., 2013; Russell-Bennett et al., 2013). Furthermore, health promotion and social marketing are widely acknowledged as close partners in transforming individuals and society toward well-being goals. Social marketing efforts exhort consumers to be active and informed participants in their health decisions. Indeed, consumers and particularly health-care consumers are increasingly required to be informed, capable and accountable, with rights to knowledge as well as being capable and free to exercise their choices (Light, 2010; McColl-Kennedy et al., 2017; Petersen and Lupton, 1996). The model of the empowered and engaged consumer where health and wellbeing is "everybody's business" (Jones, 2010, p. 2) brings altered responsibilities and changed roles (Fox and Ward, 2006; Giesler and Veresiu, 2014). From a service perspective [1], this shift to the empowered health-care consumer implies "shared accountability for resource integration among all resource-integration actors" (Anderson et al., 2016, p. 264) that in turn requires resource capabilities and service infrastructure to encourage mutual value creation (Edvardsson et al., 2014). With increasing emphasis on consumer co-

Received 28 September 2018

Revised 23 May 2019

Accepted 10 June 2019 
production - the expectation of informed and engaged consumers supporting value generation processes - Anderson et al. (2016) argue for new constructs such as consumer service literacy in TSR to better understand the interrelationships between actor resources, individual agency and institutional systems in these processes.

Literacy in its most basic sense refers to the "ability to interpret and communicate meaning through socially constructed symbols and texts" (Anderson, 2009, p. 30). Service literacy is more specifically "a customer's domainspecific expertise related to a co-production task" (Mende et al., 2017, p. 138) that clearly influences value-creating activities and service outcomes (Anderson et al., 2016; Elwyn et al., 2012; Gallan et al., 2018). From the service perspective of resource integration for mutual benefit, literacy becomes an important resource that actors can access to enable effective coproduction and participation (Payne et al., 2008). Health literacy, a domain-specific service literacy, has long been recognized as integral to constructive health-care service relationships and beneficial health outcomes (Adkins and Corus, 2009; Osborne et al., 2013; Sørensen et al., 2012).

Traditionally health literacy was defined as functional reading and writing skills in a health context. However, contemporary health researchers re-define it as "the personal and relational factors that affect a person's ability to acquire, understand and use information about health and health services" (Batterham et al., 2016, p. 1). This broadened definition incorporating functional literacy with relational, service system and service processes literacy parallels the service literacy construct and in this paper we use the term health service literacy. Accordingly, health service literacy is an integral part of patients' and healthcare service providers' (HSPs) roles as resource integrators in the service interaction (Grönroos, 2011). Using the concept of resource integration as "the incorporation of an actor's resources into the processes of other actors" (Gummesson and Mele, 2010, p. 192) for mutual value creation, this research examines health service literacy within social and institutional practices and contexts (Vargo and Lusch, 2016) to understand how service literacy engages with well-being and social change transformations. Building on prior work, we specify health service literacy roles as adopted sets of practices, based on health (and health service) expertise, related to service interactions with others in a health co-production task (Akaka and Chandler, 2011; Anderson et al., 2016; Mende et al., 2017).

As the practices that constitute roles help frame jurisdictions in service relationships and often prescribing access to resources, roles and relationships are crucial resources in value co-creation (Cheung and McColl-Kennedy, 2015; Lusch et al., 2010). Mobilization of these available resources through participation processes encourage value co-creation since the activities of one actor influence the co-creating activities of the other (Kasnakoglu, 2016). If neither partner reciprocally and actively integrates the resources available, resource integration is hindered (Vafeas et al., 2016). For example, in expert-service systems such as health care where asymmetric expertise persists, resources may not be available, mobilized or integrated due to misalignment of actors' needs, expectations, capabilities and roles (Plé and Chumpitaz-Cáceres, 2010). At times, health-care providers may consider their resources ill-suited to patient needs and withhold complex information from resource integrating activities (Hibbard and Greene, 2013), engaging in competing health service literacy roles that hinder transformative service outcomes. Conversely, patients may access self-generated resources (knowledge, skills, and motivation, McColl-Kennedy et al., 2012) that are recognized by the service provider (in the service interactions) who complements patients' resources with his/her own health service literacy role, maximizing resource integration and value co-creation. Service literacy, specifically health service literacy, is implicated in the application of resources that encourage or inhibit the value co-creation process (Grönroos and Gummerus, 2014). While scholars agree that actors' value cocreation practices need increased operationalization (Grönroos and Gummerus, 2014; McColl-Kennedy et al., 2012), service researchers have paid little attention to complementary and competing health service literacy roles.

To further our understanding of complementary and competing health service literacy roles as resource integration practices in well-being and social change transformations, we pose two research questions:

RQ1. How do patients and health service providers enact health service literacy roles?

RQ2. How do complementary and competing health service literacy roles influence resource integration in transformative services?

The study makes several contributions. First, we integrate the literature on actor roles from a service perspective with health literacy to better understand resource integration in transformative services. Second, we propose that complementary health service literacy roles are needed to enhance value co-creation. Drawing on our service literacy approach in health care we extend Frow et al.'s (2016) list of cocreation practices in transformative services, adding: practices that complement actors' service literacy roles (Figure 1). Finally, by providing a deeper understanding of actors' health service literacy roles as a nexus of resources situated within service design systems and institutional structures, we offer managerial implications for service professionals, particularly those engaged in expert transformative service systems.

This paper first integrates literature on actor roles from a service perspective with health literacy, concluding with definitions of complementary and competing health service literacy roles. The method is then described and the findings presented. Complementary and competing health service literacy roles are discussed and the section concludes with a conceptual framework. We then present theoretical and managerial implications of health service literacy roles for resource integration and transformative health-care outcomes.

\section{Literature review}

To explore complementary health service literacy roles in transformative services, this section reviews the literature on actor roles from a service perspective including dimensions of role readiness and individual agency. An overview of health literacy research is then provided. We then present complementary health service literacy roles leading to our extended typology of co-creation practices. 
Figure 1 Integration of complementary service literacy roles and Frow et al.'s (2016) co-creation practices

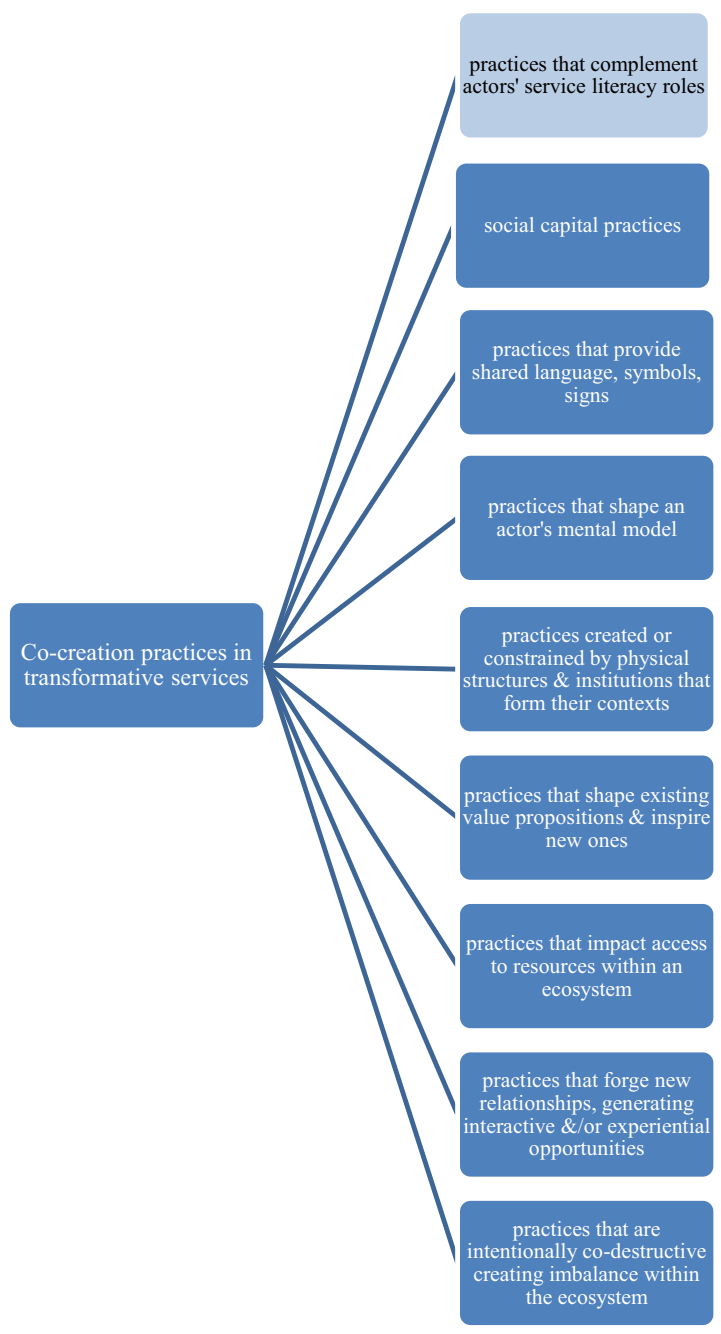

\subsection{Roles as resource integration practices}

Resources are those tangible and intangible elements that actors access, mobilize and apply within a service system to create value (Edvardsson et al., 2014). These resources, such as knowledge, skills, routines, competences and the interaction process itself, have no value per se but require integration to become uniquely valuable to actors (Grönroos and Ravald, 2011; Mele et al., 2010). Roles are adopted sets of practices (Akaka and Chandler, 2011) that shape behaviors and activities, structuring actors' resources and how they are mobilized in service interactions and influence agency in service systems (Cheung and McCollKennedy, 2015; Grönroos and Gummerus, 2014). Moreover, actor roles are dynamic, embodying social meanings, highlighting their importance as a stock of resource integration practices (Cheung and McColl-Kennedy, 2015).

\subsubsection{Roles and role readiness}

Roles have long been recognized as fundamental in service encounters (Holt, 1995; Solomon et al., 1985) and, more recently, research has specifically associated roles with value cocreation (Akaka and Chandler, 2011; Keeling et al., 2018).
Roles centre on activities that are the observable enactment of the structural dimensions of roles, namely, social position and expectations influenced by values, norms and beliefs (Moeller et al., 2013). Therefore, an individual's understanding of their world underpins his/her role practices (Frow et al., 2016).

Moreover, roles may be simultaneously salient as individuals shift between role activities according to different situations, motivation, knowledge, skills and "in response to the imputed roles of others" (Lynch, 2007, p. 384). By providing clarity around expectations, roles are an important resource for the purposeful construction of relationships (Solomon et al., 1985); for example, roles grant relational legitimacy, allow claims on various other service resources and set boundaries in service relationships (Cheung and McColl-Kennedy, 2015). In transformative services, that are typically credence-based, role expectations and role enactments are often highly prescribed being particularly shaped by normative guidelines (Solomon et al., 1985).

Roles are an important nexus of operant resources that influence actors' effectiveness as resource integrators (Lusch et al., 2010). However, resource-integration capability is more than just the application of role practices. Role identification (the degree to which customers accept and internalize their roles in participation) and role readiness - defined as actors' readiness to participate in their co-creator roles (Verleye, 2015) - have been found to significantly influence resource mobilization and value co-creation (Dong et al., 2015; Vargo and Lusch, 2004). Specifically, Meuter et al. (2005) describe role readiness according to role motivation, clarity and ability. Conceptually and empirically, improved role readiness has been linked to organizational socialization where customers develop skills, knowledge and attitudes relevant to the service encounter (Verleye et al., 2014). Therefore, actors' role readiness will also impact resource integration through their willingness to participate in accessing and mobilizing the requisite skills for the coproduction/value co-creation task. Actors' resource-integrating roles are therefore inherently dynamic and variable as these underlying dimensions vary.

\subsubsection{Roles and individual agency}

The concepts of roles and role enactment inevitably bring into play the relationship between individual agency and collective structure. Sociologists have long recognized that "society consists of both powerful determining structures, and actors that possess a degree of efficacy, freedom and creative independence" (Callero, 1994, p. 228). Using Giddens (1984) structuration theory, transformative service systems are directed by norms, procedures and beliefs surrounding the service relationship (Edvardsson et al., 2014; Gonçalves et al., 2018). Within this structural context, human agency, defined as including aspects of efficacy, competency, freedom and choice (Anderson et al., 2016), enables actors to act upon resources to create value. Importantly, human agency "depends profoundly on their [individual person's] positions in collective organizations” (Sewell, 1992, p. 21) For example, patients at times may lack agency to voice their needs, to decide what risks they can manage, and to express and act on their satisfaction or dissatisfaction. Structural asymmetry in transformative health services can also hinder actors' agency 
due to prescribed roles and processes that influence access to resources potentially limiting actors' own capability building.

Thus, role practices collectively implicate actors' service literacy as literacy skills (both reading and writing literacy as well as relational and system processes literacy) are resources that can equip actors in fulfilling their roles, particularly in expert-service systems.

\subsection{Health service literacy roles}

Health literacy has evolved from being viewed as literacy skills reading, writing and numeracy (Nutbeam, 2000; Osborne et al., 2013) - in a health setting to include: knowledge and information abilities; ability to engage with health-care providers (Osborne et al., 2013); dimensions of individual control, empowerment and motivation (Schulz and Nakamoto, 2012); and decision-making (Sørensen et al., 2012). One definition views health literacy as "all of the factors that affect the way consumers relate to the health system and the resulting outcomes" (ACSQHC Australian Commission on Safety and Quality in Health Care, 2013, p. 11). Schulz and Nakamoto (2012) reiterate that health literacy is more than knowledge elements by emphasizing aspects of empowerment and motivation. For example, while patient empowerment and health literacy may go hand-in-hand, individuals who have high health service literacy may be constrained in their resource integration activities and disempowered due to servicegenerated characteristics. Thus while early definitions of health literacy focused on literacy as an individual resource, current researchers emphasize the relational and interactional dimensions (Batterham et al., 2016) and the complex service system contexts within which health-care consumers act. Corresponding with the service perspective of value-creating resources, health service literacy encompasses skills, understandings and abilities that lead to behaviors and role expectations in service interaction contexts.

\subsubsection{Complementary and competing health service literacy roles}

Resources exist in the network of institutions and service systems and in service relationships. Thus, actors' health service literacy roles are a nexus of resources situated within service design systems and institutional structures. As resources only have value when they are deployed in resource integration (Edvardsson et al., 2014; Vargo and Lusch, 2008), their potential can be realized or negated by either supportive or competing actors' activities, service systems and role expectations. Actors' resource integration goals and efforts may not align. Tensions may exist between service literacy roles and boundaries of responsibilities in resource integration. For example, when patients have the skills and capabilities to make empowered health decisions and their health service literacy is recognized and facilitated by health service professionals, resources are effectively mobilized creating transformative outcomes. We identify this as demonstrating complementary health service literacy roles. Conversely, when health service professionals expect patients to exercise self-management and autonomy in their health-care decisions but the patient seeks professional guidance with minimal co-production activities, health service literacy roles are misaligned or competing. Competing roles also limit resource integration when HSPs fail to account for patients' high levels of agency and role readiness, resisting demands for patient-centred decision-making and instead exercising their autonomy over patient care. These terms provide the framework for this study.

\subsubsection{Health service literacy roles and co-creation practices}

Value co-creation occurs when both service provider and customer actively participate in resource integration of focal operant resources such as knowledge, skills and service literacy roles to mutually realize a desired outcome (Grönroos and Ravald, 2011). Researchers have sought to identify customers' co-creation practices within the system of resource integrating actors (McColl-Kennedy et al., 2012; Moeller et al., 2013; Sweeney et al., 2015; Tommasetti et al., 2017). From the firm perspective, Prahalad and Ramaswamy (2004) use the DART framework of dialogue, access, risk and transparency to describe firm activities in value co-creation. Across the various typologies the common theme is that the purpose of these value co-creation practices is "to access resources, correct[ing] resource deficiencies and improve[ing] resource density" (Frow et al., 2016, p. 24) leading to resource integration and mutual benefit. This research uses the Frow et al. (2016) typology of co-creation practices for three reasons: it includes both beneficial and destructive practices, it applies to actors within a service ecosystem (not just customers) and thirdly, it is developed in, and particularly relevant to, the context of health care.

The typology of Frow et al.'s (2016) original eight cocreation practices is illustrated in Figure 1. Based on the literature review we extend this typology with an additional cocreation practice termed - practices that complement actors' service literacy roles.

\section{Method}

\subsection{Research approach}

Although service literacy is acknowledged as influencing value creating activities particularly in transformative services, little is understood of how health service literacy roles influence resource integration. The qualitative research method allowed the researchers to explore these constructs in a transformative service setting among healthy consumers. The research uses an abductive research approach, specifically hermeneutics (Ricoeur, 1976). This non-positivistic methodology allows for a systematic process of moving between existing theorizing and empirical data (Dubois and Gadde, 2014). Pre-understandings from prior research and literature are deepened by insights from the data. The abductive research approach positions the study within a service perspective, focusing on complementary health service literacy roles within resource integration (Dubois and Gadde, 2014; Heinonen, 2018).

\subsection{Research design}

In total, 57 in-depth semi-structured interviews (46 with primary health-care patients and 11 with health-care service providers) were conducted over five months[2]. The average length of interviews was 43 minutes for patient participants and $52 \mathrm{~min}$ for HSP participants. The interviews were recorded and transcribed verbatim (resulting in 787 single-spaced pages of textual data) before being imported into ATLAS.ti 7.1.6.

Primary health-care patients were recruited using a purposeful stratified sampling strategy based on age (baby 
boomers born 1946-1965), gender and ethnicity (Miles and Huberman, 1994). Gender and ethnicity were purposefully chosen as they both differentially impact the use and experience of health-care services (World Health Organisation WHO, 2010). Participants were recruited through referrals and snowballing and data saturation was reached at 46 patients (Patton, 2002). Baby boomers are generally characterized as having particular concerns over their health challenging existing models of service (Huber and Skidmore, 2003; Noble et al., 2004; Phillipson et al., 2008; Quine and Carter, 2006) making them rich informants for this study.

The interview questions followed a topic guide based on the communicative, critical, contextual, and functional dimensions of health literacy (Chinn, 2011; Nutbeam, 2000). Participants were asked to talk about their experiences; for example, how they look after their health, how they seek health advice, who they interact with regarding health advice and how they access health information. Moving from general questions to more specific questions, patients were asked about their health care service experiences, how they relate to their HSP, and how they respond to satisfactory/unsatisfactory interactions.
Characteristics of the patient participants and HSPs are summarized in Table I.

Each patient completed a self-reported health status scale, and a 13-item all aspects health literacy scale (AAHLS, Chinn and McCarthy, 2013). The AAHLS was applied after the recruitment of participants to further describe the sample (Table I). Age and ethnicity did not appear to be a factor in the AAHLS scores. Answers to pre-interview questions on selfreported health and health professional visits indicate that the sample was not biased towards individuals who might be considered health experts, due to specific health conditions, nor who identified as having high health risk. The higher level of education among the participants is common in samples of volunteer research participants (Ownby et al., 2014).

Intensity sampling was used to recruit the HSPs (Patton, 2002). The HSPs were engaged in health literacy practices either directly via a general practice model or as part of a health services delivery network. The HSPs were recruited via: a local health network forum, public engagement in health literacy policy, and referral from other participants. Thus they were knowledgeable and able to provide rich information on the

Table I Sample characteristics - patients and health service providers

\begin{tabular}{lc}
\hline Patients $\mathbf{n}=\mathbf{4 6}$ & \\
Ethnicity & 12 \\
European & 12 \\
Māori & 11 \\
Pacific peoples & 11 \\
Asian & \\
Gender & 21 \\
Male M & 25 \\
Female F & \\
Age sub-group & 18 \\
Born 1946-55 (Leading edge BB) & 28 \\
Born 1956-65 (Trailing edge BB) & \\
& \\
Health Literacy (AAHLS) & score (\%) \\
Functional & 93.48 \\
Communicative & 93.96 \\
Critical & 79.76 \\
Empowerment & 67.07
\end{tabular}

Health-care service providers (HSP) $\mathrm{n}=11$ Pseudonym

Barry

Ann

Janice

Paul

Mike

Marie

Sue

Simon

Emily

Alan

Daniel

Family Medicine/Integrative Medicine practitioner

Regional Health Network advisor

Pharmacist

Audiologist

Chiropractor

Health literacy educator

Family Medicine practitioner

Family Medicine practitioner

Pharmacist

Optometrist

Dentist

Years


study phenomena. In-depth interviews were conducted with 11 HSPs where data saturation was achieved. HSPs were asked to talk about their approach to health literacy, how they experience health literacy, what needs to be in place for effective health literacy, and what factors influence their interactions in relation to health literacy.

\subsection{Analysis}

A systematic process of transcript-based analysis followed the stages of: identifying codes, developing categories, developing definitions of these categories and creating links between these categories (Martin and Turner, 1986). The ATLAS.ti software was used to organize and code the data. We used the participants' own terms to initially develop codes. The process of interpretation followed Ricoeur's (1976) hermeneutic approach, iteratively examining these codes and health service literacy roles in light of relevant theorizing and literature. Key areas of literature included consumer roles (Akaka and Chandler, 2011), patient practice styles (McColl-Kennedy et al., 2012, 2017), health literacy (Batterham et al., 2016; Schulz and Nakamoto (2012) and value co-creation practices (Frow et al., 2016; Grönroos and Ravald, 2011). The coding, categories and grouping of activities were cross-checked by two expert researchers in the health-care domain. Subsequently, four propositions were developed describing the interrelationship of categories to "assemble a story" (Creswell et al., 2007, p. 250) relating health service literacy roles and resource integration in transformative services to constructs in the conceptual framework. Examples of the coding and explanation of each health service literacy role are summarized in Tables II and III.

\section{Findings and discussion}

This section presents four propositions to address the overall purpose of the research which is to better understand how health service literacy roles, from a resource integration perspective, advance value co-creation and transformative outcomes.

\subsection{RQ1 How do patients and health-care service providers enact health service literacy roles?}

The aim of this research question was to explore how patients and health service providers enact health service literacy roles. These roles are described according to role readiness dimensions resulting in two propositions linking health service literacy roles to resource integration: patients' health service literacy roles are dynamic and interdependent with role readiness and agency; and health service literacy is enacted by HSPs as managed empowerment within institutional norms and service system processes.

\subsubsection{Proposition 1: Patients' health service literacy roles are dynamic and interdependent with role readiness and agency} Our data reveal that patients define health service literacy according to five key roles whereby they integrate resources in health-care service relationships: seeker, decider, networker, sensemaker and manager. As it would take up too much space to present these roles in the text, the explanation of them and the corresponding role readiness dimensions appear in Table II. The characteristics of each role are also described with a short informative sentence. Illustrative quotes from the data are included in the table.

Patients actively integrate multiple resources at different levels (informal networks, professional networks) and at varying levels of intensity and complexity. Patients sometimes co-create value with the health-care service provider, but may also create value in other ways. For example, patients who experience health literacy as networking and sense-making often integrate resources independently of the service provider, taking responsibility for their health choices and exercising agency. Health service literacy roles may be temporary (according to the patient's health situation) and they may be responsive to other network actors (including service providers). While some patients typically self-identify with a particular role, many defined health service literacy as multifaceted. Patients associate health literacy with effort they are willing to exert to achieve value in primary health care (Sweeney et al., 2015), but always emphasize health service literacy as dynamic, within the health and service context, and interdependent with their role readiness to exercise individual agency. This variability of health service literacy roles is evidenced in one patient's data; from wanting to be in charge:

So I'm always just checking with the information I've known before in terms of what's happening [...] information that I've been building on for a lifetime. (Patient 17, F, Māori, Trailing edge BB)

to using all of her health network resources (including the service provider) for creating value:

[I use] my networks - family and friends, social networks, yeah, professional networks [...] it's got to make sense. (Patient 17, F, Māori, Trailing edge BB)

to putting responsibility back on the HSP:

I don't want to do a medical degree while I'm sitting in the interview with the doctor. (Patient 17, F, Māori, Trailing edge BB)

Importantly, patients' health service literacy and individual agency is inextricably related to the relationship with their service provider. Role expectations of the HSP vary within changing health contexts placing emphasis on communication and relationships for successful resource mobilization and integration.

\subsubsection{Proposition 2: Health service literacy is enacted by health- care service providers as managed empowerment within institutional norms and service system processes}

The analysis revealed three main HSPs' health literacy roles: knowledge broker, ethical agent and enabler and corresponding role readiness features. The characteristics of each role are explained in Table III. HSPs' health service literacy roles are largely guided by the institutional norms and values of their professional groups, training and service delivery structures. The influence of institutional logics and social structures in value co-creation is increasingly stressed by service scholars (Edvardsson et al., 2014; Vargo and Lusch, 2016). Our HSPs, for example, indicated how their intentions and capabilities (i.e. agency) in terms of health service literacy are shaped by the current values and expectations of their profession. Although HSPs provide their patients with informed choice in many areas, there are often underlying power and information imbalances, conflicting authority concerns, and perceived threats to their professionalism. Through their health service literacy roles HSPs reluctantly 
Table II Patients health service literacy roles and role readiness

\begin{tabular}{ll}
\hline $\begin{array}{l}\text { Health service } \\
\text { literacy role }\end{array}$ & Explanation \\
\hline Seeker & $\begin{array}{l}\text { Purposefully uses information gathering and evaluative skills. } \\
\text { Organizes information in a predominantly cognitive process. } \\
\text { Characterized by: } \\
\text { Searching - identifies information sources to retrieve relevant } \\
\text { information } \\
\text { Organising - sorts information according to health context } \\
\text { Evaluating - seeks justification and evidence to verify health } \\
\text { information }\end{array}$ \\
& \\
& \\
Decider & $\begin{array}{l}\text { Actively engages in health decisions. } \\
\text { Exercises individual discretion over health literacy behaviours. } \\
\text { Characterized by: } \\
\text { Choosing - understands opportunities using own discretion } \\
\text { to exercise choice } \\
\text { Acting - uses abilities and skills to be proactive in health } \\
\text { decisions } \\
\text { Taking responsibility - demonstrates self-determination to } \\
\text { meet health service needs }\end{array}$
\end{tabular}

Networker

Sensemaker

Manager
Is highly connected, keen to share knowledge within their social network

Is respected by others for their knowledge and advice; the person others often turn to.

Characterized by:

Relating - committed to relationships with others of shared values

Connecting - shares and receives advice within referral networks

Partnering - leverages collective knowledge for health decisions

Makes sense of health information, pragmatically directing their own health

Experiments and seeks alternatives and opportunities, relies on evidence and outcomes

Characterized by:

Experimenting - improvises and engages in trial and error Experiencing - uses past experience to build plausible interpretation of health cues and solve problems [Self] Understanding - uses reflection to develop awareness of self

Focusses on dependable relationships and an understanding of systems and processes for value-creating practices.

Characterized by:

Integrating - integrates multiple health resources
Role readiness dimensions

Role motivation:

"I know there are big changes in the treatment of [xxx] going on, so I want to be aware if anything changes. (Patient $4, M$, European,

Trailing edge $\mathrm{BB}$ )

Role clarity:

"I'm always enquiring about and always looking and reading about general health issues, in terms of general maintaining of good health especially as I get older." (Patient 43, M, European, Leading edge BB) Role ability:

"I always check with those that have had the training and talk to them, "What do you think of this? Is that right or wrong?" (Patient 12, F, Asian, Trailing edge BB)

Role motivation:

"I've decided I'll apply a conscious approach to my decision making about what I eat, and how I exercise." (Patient 14, M, Pacific Peoples, Trailing edge BB)

Role clarity:

"So I went to our GP [family doctor] and said, 'Look, I want this [done] because I thought it's my body and this is what I want'." (Patient 10, $F$, European, Leading edge BB)

Role ability:

"I had four times the maximum recommended by the World Health Organization. So yeah, things weren't looking good. I really had to do that myself; come to that conclusion myself." (Patient 8, F, European, Leading edge $\mathrm{BB}$ )

Role motivation:

"We can do it [lifestyle, good health outcomes] collectively ... with the help of others it's really boosted up what I can do." (Patient 38, M, Pacific Peoples, Trailing edge BB)

Role clarity:

"Yeah if there's stuff out there that is available for our people then we try and inform them so that they can try and access it too." (Patient 21, F, Pacific Peoples, Trailing edge BB)

Role ability:

"I use family and friends, social networks, professional networks. People that I know that may have had some similar sort of issue ... that's me - connected." (Patient 17, F, Māori, Trailing edge BB) Role motivation:

"It's no good doing a lot of things when you don't really know why you are doing them. I want to know why I have to do what they say; everything has to fall into place" (Patient 45, M, Māori, Trailing edge $\mathrm{BB})$

Role clarity:

"Well, he [HSP] couldn't explain what was wrong with me so I thought, well, I'll just keep looking." (Patient 6, F, European, Trailing edge BB)

Role ability:

"I'm very good at listening to my own body and I know it well enough now to know when things don't feel in balance or feel right." (Patient $11, \mathrm{~F}$, European, Leading edge BB)

Role motivation:

"I want to be part of the process of getting better or staying healthy, as opposed to just going there and getting fixed." (Patient 36, F, Māori, Leading edge BB) 
Table II

\begin{tabular}{lll}
\hline $\begin{array}{l}\text { Health service } \\
\text { literacy role }\end{array}$ & Explanation & Role readiness dimensions \\
\hline & (information, actors, networks) with their own skills & $\begin{array}{l}\text { Role clarity: } \\
\text { "We're [GP and patient] honest with one another. We don't beat } \\
\text { about the bush or anything like that. We just say it as it is, yeah, he's } \\
\end{array}$ \\
\cline { 2 - 3 } & $\begin{array}{l}\text { Directing - negotiates responsibilities with various actors } \\
\text { Growing - expands capability and knowledge by being }\end{array}$ & $\begin{array}{l}\text { Role ability: } \\
\text { "It's just communication ... I communicate to him what I want, or } \\
\text { responsive to opportunities }\end{array}$ \\
& $\begin{array}{l}\text { what I would like out of the health system." (Patient 5, M, European, } \\
\text { Leading edge BB) }\end{array}$ \\
\hline
\end{tabular}

Table III Health service providers' health service literacy roles and role readiness

\begin{tabular}{|c|c|c|}
\hline Health service literacy role & Explanation & Role readiness \\
\hline Knowledge broker & $\begin{array}{l}\text { Practices that evaluate the patients' needs for } \\
\text { information and sort, interpret, and validate health } \\
\text { information for patients } \\
\text { Evaluating and screening information for relevance and } \\
\text { meaningfulness to patients } \\
\text { Characterized by: } \\
\text { Interpreting and validating health information - handles } \\
\text { information and interprets it for patients } \\
\text { Being an information gatekeeper - exercises their } \\
\text { obligation to provide patients with accurate information } \\
\text { Acting as a gatekeeper to health-care options - directs } \\
\text { patients' choices through the health-care system/ } \\
\text { treatment options }\end{array}$ & $\begin{array}{l}\text { Role motivation: } \\
\text { "[... .] we're the gatekeepers and we generally open the gate." } \\
\text { (Sue) } \\
\text { Role clarity: } \\
\text { "[... II've got to take complex clinical information, digest it, and } \\
\text { turn it into a form that's going to be readily digested by somebody } \\
\text { who has some knowledge without changing what that really } \\
\text { means." (Mike) } \\
\text { Role ability: } \\
\text { "The thing is recognizing what's good and what's not on the } \\
\text { Internet and that's where it's our job to guide people." (Daniel) }\end{array}$ \\
\hline Ethical agent & $\begin{array}{l}\text { Perspectives and practices that use professionalism as } \\
\text { the basis for trust and authority } \\
\text { Emphasizes the use of authentic professional knowledge. } \\
\text { Characterized by: } \\
\text { Being fair and equitable - adopts fair and unbiased } \\
\text { practices in a non-opportunistic manner } \\
\text { Acting with professionalism - takes responsibility for } \\
\text { patient well-being, promoting health and health services }\end{array}$ & $\begin{array}{l}\text { Role motivation: } \\
\text { "I have to own him, he's one of mine. I am a health professional } \\
\text { and I have to pick up some responsibility for his behavior." } \\
\text { (Janice) } \\
\text { Role clarity: } \\
\text { " [...] I'm responsible for looking after you and I know what's } \\
\text { right." (Mike) } \\
\text { Role ability: } \\
\text { " [. . . ] we send people reminder s [...] that it's time to come in } \\
\text { again, and we always have the eye health message. We never } \\
\text { promote any products or anything like that." (Alan) }\end{array}$ \\
\hline Enabler & $\begin{array}{l}\text { Actions that encourage, motivate, and support patients } \\
\text { to be health literate in the broadest sense } \\
\text { Sharing in learning new knowledge and engaging in new } \\
\text { forms of health knowledge } \\
\text { Characterized by: } \\
\text { Integrating resources - uses diverse resources in } \\
\text { exchanging health ideas and insights } \\
\text { Being a partner and co-learner - shares in learning new } \\
\text { knowledge and engages in new forms of health } \\
\text { knowledge }\end{array}$ & $\begin{array}{l}\text { Role motivation: } \\
\text { "We talk to people [. . .] we try and make other people's journeys } \\
\text { better." (Marie) } \\
\text { Role clarity: } \\
\text { " [. . . I I don't see myself sitting above somebody [the patient]; we } \\
\text { see ourselves as sitting alongside people. We're there to be used } \\
\text { as a resource." (Janice) } \\
\text { Role ability: } \\
\text { "I do my own research [...] look up information they give me } \\
\text { [. . .] it's about trying to expand my knowledge base as well." } \\
\text { (Barry) }\end{array}$ \\
\hline
\end{tabular}

acknowledge the blurring of boundaries between expert and lay health knowledge (Light, 2010) but reinforce their professional expertise by adopting practices of brokering information, applying technical knowledge and building relationships. Collectively, HSPs' exercise managed empowerment through these health service literacy roles that respond to dynamic patient preferences for information, choice, and autonomy. Managed empowerment enables HSPs to re-negotiate their professional authority (Light, 2010), re-negotiate relationship and role expectations, and redefine their expertise in the health-care service interaction (Elwyn et al., 2012; Thorne et al., 2013). 


\subsection{RQ2. How do complementary and competing health service literacy roles influence value co-creation in transformative services?}

The aim of this research question is to understand how service literacy roles of patients and HSPs align to enhance or diminish value co-creation and value creation. Patients may be unable to exercise choice and agency due to structures and processes in transformative services. HSPs' service literacy roles, being embedded in and shaped by institutional norms and beliefs, may also enhance or constrain well-being outcomes. We offer two propositions that link health service literacy roles to resource integration: complementary service literacy roles elicit outcomes of respect, trust, empowerment and loyalty through successful resource integration; and competing service literacy roles lead to outcomes of discredit, frustration, resistance and exit through unsuccessful resource integration.

\subsubsection{Proposition 3: Complementary service literacy roles elicit out-} comes of respect, trust, empowerment and loyalty through successful resource integration

Complementary health service literacy roles help individuals to draw on their own competencies and to integrate resources in the service relationship for value creation. Four outcomes emerged from the data relating to value creation: respect, trust, empowerment and loyalty. In our data, we found these were common to both patients and HSPs. For example, patients who are practised information-seekers need their level of knowing to be taken seriously. When their sense of entitlement to information was understood by HSPs, patients experienced enhanced value in the form of respect:

There's a sense of openness and willingness to hear one another, there's no condescension, no arrogance involved. (Patient 8, F, European, Leading edge $\mathrm{BB})$

Also, HSPs experience respect when patients' role practices relied on HSPs' professional expertise as a knowledge broker:

I want the patient to say, "I' $m$ on board with that because I agree with your line of reasoning”. (Mike, HSP)

Trust also occurs when role practices are supported reciprocally during the service relationship. Although choice is empowering, patients associate choice as a precarious freedom that demands responsibility (Anderson et al., 2016); for patients who perceive the HSP as the enabler for their responsibility trust is a value-enhancing outcome:

[...] I could go to my doctor and I trust her [and] I just don't have to bother with all of this stuff when things happen, just hand it [responsibility] over [...] (Patient $8, \mathrm{~F}$, European, Leading edge BB)

Patients often make health decisions under conditions of imperfect information, uncertainty, emotional involvement, and risk (Schneider and Hall, 2009). Patients as information seekers typically allow the HSP to exercise judgment on their behalf, particularly regarding competing knowledge claims. HSPs who complement the patient's health literacy and recognize this need:

[...] so what I do is give them information about whatever's wrong and then we'll sort of basically talk about what they can do to fix it. It's really like a negotiation. (Barry, HSP)

experience trust and a constructive relationship.

It's that relationship of having a patient seeing you through their illnesses, knowing their whole family. (Barry, HSP)
Equally, when patients re-negotiate traditional patientpractitioner roles and enact sensemaker and manager roles, HSPs become trusted partners in the collaborative relationship:

the ones [HSPs] I've dealt with have basically given me real options and choice and basically it's been up to me. (Patient 13, M, European, Leading edge BB)

Furthermore, enacting health service literacy as an enabler the HSP creates opportunities for patients to have a voice in making health-related decisions. HSPs are empowered when they are instrumental in patient engagement with health, for example:

[...] so that people want to participate in their healthcare, saying, 'Well what can I do; how can I help myself; what changes can I make' [...] that's the best thing for me. (Mike, HSP)

Loyalty, the fourth outcome revealed in our data, emphasizes reciprocal relationships of rights and responsibilities as a foundation for constructive service relationships. We found loyalty was a purposeful choice among patients and HSPs. Patients were consistent and loyal when HSPs genuinely brought their information resources, professional expertise and responsibility, and service networks (i.e. the logic of care, Mol, 2008) to the health service relationship. In other words, enacting the enabler roles to complement sensemaker roles in patients leads to loyalty which is constructive for HSPs:

But if you'd like to go on this journey with us well then that would be even better from our perspective because we think we might be able to assist you on a longer term basis. (Mike, HSP)

and for patients:

[.. Jif anything happens, my thoughts go straight away to my GP [family doctor]. I've never really thought of looking anywhere else (Patient 46, M, Maori, Leading edge $\mathrm{BB}$ )

\subsubsection{Proposition 4: Competing service literacy roles lead to out-} comes of discredit, frustration, resistance and exit through unsuccessful resource integration

When service actors fail to recognize (either accidentally or deliberately) others' health service literacy roles, value is decreased. The four outcomes to emerge from the data resulting from competing service literacy roles and thus unsuccessful resource integration - discredit, frustration, resistance and exit - are common to both patients and HSPs.

Patients felt discredited when their expectations and selfknowledge were treated superficially. For example:

"I just really felt, she treated me like, you're not a medical person; you don't know what you're talking about" (Patient 13, M, European, Leading edge BB)

Often, HSPs' attention to workflow requirements and service delivery processes resulted in inadequate communication, interpreted by patients as dismissal:

Sometimes when I've been there I get a feeling of I've interrupted and that they're annoyed. Like it's quick, it's fast and it's all over and out you go. So to me there's no real one-on-one relationship type talk. (Patient 42, M, Māori, Trailing edge $\mathrm{BB})$

Similarly, HSPs, faced with unpredictable challenges to their role and professionalism, experience a sense of dismissal, for example:

"patients think they don't need to listen our message." Alan) and "[...] they [patients] listen to their neighbor rather than their doctor or their pharmacist". (Emily, HSP)

Frustration, an outcome where mutual value is diminished, occurs when the HSP regards the patient as having inadequate 
capabilities yet the patient perceives his/her health service literacy and role readiness to be adequate. For example, patients experienced limited collaboration or perceived information bias from the HSP which reduced the efficacy of the patient's seeker practices and role readiness. Patients' selfresponsibility intentions can be hindered by a lack of sense of urgency by HSPs, thwarting the exercise of patients' individual agency increasing uncertainty over efficacy of options for meeting their needs. Resources are neither successfully mobilized nor integrated. As one patient stated:

Yeah it's me, every day, that's upset by these headaches [...] so putting me on pills for a month to see if it'll go away is not OK. (Patient 3, F, European, Leading edge $\mathrm{BB}$ )

Similarly, frustration and futility are common expressions of diminished value among HSPs when patients prefer a different logic, alternative rationale or different strategies challenging a HSP's judgement.

Evidence of resistance among patients is found on various levels. Patients resist health promotion messages and they resist options that conflict with their health view and lay knowledge, preserving their self-understanding and self-identity (Weick, 1995). For example:

We get an alarmingly bad return on health promotion messages [...] because by the time they find the [glaucoma] symptoms it's often too late. (Alan, HSP)

HSPs resist changes that challenge their professional authority, choosing to avoid participation at the level demanded by the patient or delaying open communication with patients such as online patient portals. Patient demands for certain types of care, treatment or information can be perceived by HSPs as a form of regulation which can be met with resistance.

It's almost like the patient takes control; this is the modern patient [...] a secure portal that the patient can go in and they can look at their results, their consultation notes - although we're not going to turn that on just yet. (Sue, HSP)

Finally, exit is a typical outcome of unsuccessful resource integration. For patients, exit followed their dissatisfaction with lack of responsiveness and tailored support according to their service literacy roles. System processes that do not accommodate patients' preventive health behaviors inhibit role readiness and individual agency. Patients exited rather than confronting or challenging their HSP:

We've got control over what we want to do. If he [family doctor] isn't helping, well, I go somewhere else and find what I want. (Patient 10, F, European, Leading edge $\mathrm{BB}$ )

For HSPs, exit was more subtle as they balanced their autonomy over patient care with patient-driven autonomy, sometimes withdrawing when conflicts over patient care where unresolvable:

When the patient says, "This is what I want to do, I don't want to take your medicine, I don't believe in your medicine" then your therapeutic relationship has broken down (Sue, HSP)

From a service perspective, unsuccessful resource integration results from competing health service literacy roles and the interplay of actor resources and health context.

\subsubsection{Implications of complementary and competing roles}

Our findings on complementary roles highlight that a resource only has value in certain contexts and for certain actors (Vargo and Lusch, 2004). Resource integration is not solely to do with capability and motivation, depending as well on the interaction of multiple processes and activities (Anderson et al., 2016), importantly complementary and competing health service literacy roles. HSPs' knowledge-broking roles became resources interactively with seeker role practices for certain health services (such as test results, standard medical checkups, routine preventive screening), resulting in value enhancement outcomes of respect and trust. From these outcomes constructive relationships can be developed. However, the interplay of knowledge-broking roles with patients' health service literacy roles as managers led to unsuccessful resource integration and feelings of frustration and dismissal:

I'll go there and say, "This is how I understand it, what am I missing?" Quite often there's a little bit of that smirking thing like "here we go, another homelearned doctor”. (Patient 17, F, Māori, Trailing edge BB)

Yet when patient roles as managers were complemented by HSP enabler roles the patients felt respected (increased value). Successful resource integration occurred when HSPs aligned their resources, expertise, networks, and professional responsibility with the patient's health service literacy roles:

There's a sense of openness and willingness to hear one another, there's no condescension, no arrogance involved. (Patient 8, F, European, Leading Edge $\mathrm{BB})$

The questioning, problem-solving, and need for self-awareness practices characterized in a patient's sensemaker role became resources when supported by the HSP's enabling and colearning role practices, such as:

I got the connection you know (Patient 5, M, European, Leading edge BB)

[.. .] everything fell into place and I thought, "Oh, is that why". (Patient 45, M, Māori, Trailing edge BB)

Finally, the asymmetric dimensions of health-care service relationships may be intentionally maintained by one actor, excluding potential resources from the service exchange interaction. Importantly, insights from our data show that patients did not always seek responsibility and agency; they envisage health service literacy roles as dynamic and negotiable. Therefore, we argue that when actors' health service literacy roles are complementary and adaptive to the service context successful resource integration occurs.

\subsection{Conceptual framework}

The purpose of this research is to better understand, using a service perspective, how health service literacy roles can advance value co-creation and transformative outcomes. In this section we present a conceptual framework (Figure 2) that summarizes the insights from our data integrated with existing theorizing from the literature.

The first level in our model, actor-level interactions, centres on complementary health service literacy roles. Patients enact service literacy roles dependent on role readiness and individual agency within a complex array of personal health situations, health beliefs, complicated service systems and institutional processes (Edvardsson et al., 2014). HSPs mobilize multiple resources and enact roles embedded in their professional expertise and institutional norms. These actor-level interactions are thus shaped by (and influence) the second level of institutional processes and service systems supporting or 
Figure $\mathbf{2}$ Complementary health service literacy roles and transformative outcomes framework

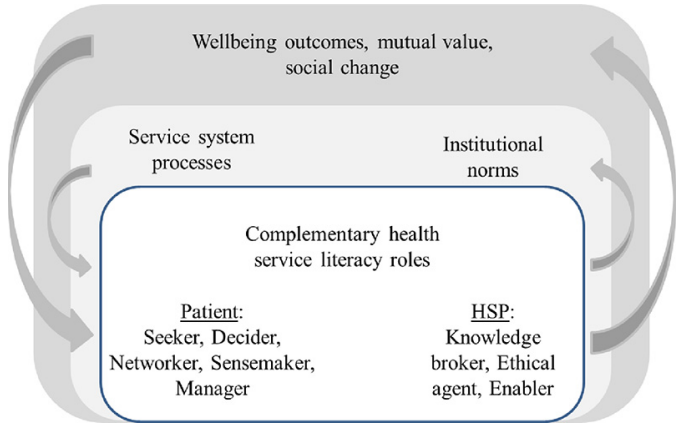

diminishing resource integration activities (illustrated as the third level).

Patients may seek expertise and service-led support to more effectively mobilize resources in the health-care service encounter. Yet service providers may not "fit into the customer's life" (Elg et al., 2012, p. 330) due to misaligned service processes, institutional norms, or conflicting expectations. Competing roles (either deliberately or mistakenly) limit effective resource integration reducing value creation. Conversely, when patient and HSP roles are complementary and constructively integrated into service system processes, successful resource integration occurs. Successful resource integration influences transformative outcomes at the actor level through well-being and mutual value creation. In addition, system level transformations and social change can occur, the final level in our framework. At the system level, service processes can be more efficient. For example, when roles are complementary patients efficiently access preferred treatment options avoiding wasteful use of treatments and adhering to appropriate medications. With aligned health service literacy roles patients will experience deepened trust that the HSP is genuinely patient-centric, concerned about their experience of health and their needs as a consumer. In turn, patients' enhanced capabilities and participation in mobilizing resources improves their health-care compliance behaviours, such as monitoring blood sugar levels or joining immunization programmes (Schulz and Nakamoto, 2012), in turn meeting social change and public health goals.

Competing health service literacy roles can hinder resource integration and the positive developments indicated in the conceptual model. The current demands for the democratization of health and patient autonomy can mean that HSPs misjudge patients' service literacy and role readiness (motivation and competencies) and service system processes are ill-suited to patients seeking expert support. As a result, exercising choice becomes overwhelming and disempowering with patients' less likely to mobilize and integrate resources (Elwyn et al., 2012). Competing roles also limit resource integration when HSPs fail to account for patients' high levels of agency and role readiness. In those service literacy roles patients expect access to diverse sources of information, expertise, and shared decision-making. Institutional and system barriers may also limit these patients' access to products and services that could further improve their capabilities for resource integration and enhance well-being.
Finally, we add feedback processes of influence into our framework. Successful resource integration and transformative outcomes feed-back to enhance actor agency (Blocker and Barrios, 2015) and role readiness. Value creation for HSPs and social change outcomes also feed-back into system processes and institutional activities encouraging service support that is better tailored to service literacy roles. However, the complexities of the various types of necessary expert-service system adjustments for resource integration demand further investigation.

\section{Conclusion and implications}

The central purpose of this research was to explore complementary health service literacy roles from the perspective of resource integration. We argue that efforts toward patient empowerment will be transformational when service providers recognize and adapt to actors' health service literacy. At the service system level, complementarity of the provider's role of providing service and the user's role of consuming the service enhances well-being. With implications for consumer value (e.g. health outcomes), service provider value (e.g. professional integrity) and ultimately public value for society this research is positioned at the intersection of TSR, social marketing and service thinking.

\subsection{Implications for service and social marketing thinking}

Our research contributes to service thinking in two important ways. In health-care services, with high expertise asymmetry and perceived risk, patients typically require resources outside of their own competences. Therefore, the ability of the service provider to appropriately support customers' value creation affects transformative service outcomes (Anderson et al., 2016; Brozovic et al., 2015). The challenge for service providers is to gain insights into the idiosyncrasies of patients' resources and agency. We contribute to this issue by offering health service literacy as a means to inform our understanding of resource integration practices.

Patients not only acquire resources but also transform and act on resources in their everyday health decisions and enact dynamic roles within the transformative service relationships to co-create value. Specifically, this study highlights the negotiated processes of health service literacy roles. Actor agency and professional expertise are only realized as resources when they are acted on within a complementary framework of structures, processes and institutional logic. We therefore add a co-creation practice to Frow et al.'s (2016) list, namely, practices that complement actors' service literacy roles.

Finally, we develop a conceptual framework that summarizes the relationships between service literacy, actor agency and role readiness, illustrating how complementary health service literacy roles can advance value co-creation and transformative outcomes.

\subsection{Managerial implications}

For health service providers the inherently dynamic service literacy roles make for a "complicated dance of exerting or avoiding guidance [...]" (Thorne et al., 2013, p. 294) requiring a deep interpretive understanding by service professionals. This 
understanding is particularly challenging yet necessary in expert-service systems as these service interactions often result in competing expectations. Consumers who lack expertise may become vulnerable and resist the expectation to be empowered. Service providers may feel thwarted in their attempts to be responsible for patient welfare when consumers expect to be in charge of their health decisions. Acknowledging these complexities, we offer some suggestions for service professionals based on our empirical data:

- Encourage service encounters that enable service providers to learn something of the other's worldview and tailor the service experience accordingly (Keeling et al., 2018). This may be facilitated by community health-care networks and improved integration of multi-actor contributions within an individual's health network.

- Prioritize health service literacy discussions within consultations and facilitate the opportunity to ask questions, including appropriate health explanations and information that fosters individual agency. This may require changed professional norms around the efficacy of teams of health service providers. While service providers may not be able to influence the institutionalized service processes they can develop the ability to recognize role readiness and influence role motivations to manage successful resource integration. We recommend service providers to identify with individuals what they need so that their sense of empowerment may be reinforced or their sense of requiring support can be upheld.

- Encourage service design and system processes for complementary service literacy roles. HSPs may be prevented from value facilitation by managerially dictated workflows and treatment incentives.

- Incentivize continuity in service provider relationship to develop a shared understanding of heath service literacy. This implies changing the widespread managerial emphasis in health-care management on time and patient throughput to instead emphasizing relationship building.

- Incorporate service literacy roles in the education and continuing professional development of health-care service professionals to help tailor service interactions toward resource integration activities.

Furthermore, our findings show that good and bad health behaviors (such as non-compliance with treatment) may not be a failure of actor agency or limited consumer capabilities but represent the interplay of competing health service literacy roles, agency and service processes. This has special relevance to social marketers. Individuals may have the capabilities to act as competent resource integrators and exercise choice in certain contexts; in others, health service literacy roles of HSPs may thwart access to expertise and contest knowledge perspectives regarding health behaviors.

In summary, health service literacy and role readiness provide an important platform for building well-being outcomes. It is clear that at times value diminution occurs, wasting the resources available in the transformative service relationship. However, insights into service literacy roles provides opportunities for service providers to support successful resource integration facilitating value co-creation processes in social change and transformative services.

\subsection{Limitations and future research}

Although this research responds to the call for empirical studies capturing " $[\ldots]$ subjective value experiences in the social context" (Helkkula et al., 2012, p. 70) one limitation is its empirical focus on a single group of health-care consumers within one health-care context (primary health services). While the research participants provided rich information around shared decision-making, capability, and agency in health-care decisions, other health-care consumers and other transformative service domains are important areas to explore. Research participants had higher education than the general population so future research should include a more diverse sample to add insights regarding education and service literacy roles. Future research can also build on our four propositions by operationalizing the constructs and testing the relationships between these constructs. Research is also needed to explore health service literacy roles according to patients' health-care service journeys. The research purposefully selected participants who were not defined according to a health risk. However, a worthwhile avenue for future research is to investigate complementary and competing health service literacy roles and resource integration among patients experiencing chronic and acute medical conditions. There is also scope to investigate the influence of ethnicity and education level on complementary health service literacy roles. Finally, further research is needed to investigate role readiness and service literacy roles in service domains other than health to develop services that enhance resource integration and mutual value.

\section{Notes}

1 We use the term service perspective, drawing on some aspects from service-dominant logic such as resource integration, and some from service logic such as the treatment of co-creation as relating to the interactions between the actors.

2 The data were collected as part of the first author's PhD research.

\section{References}

ACSQHC Australian Commission on Safety and Quality in Health Care (2013), "Consumers, the health system and health literacy: taking action to improve safety and quality", Consultation Paper, ACSQHC, Sydney.

Adkins, N.R. and Corus, C. (2009), "Health literacy for improved health outcomes: effective capital in the marketplace", fournal of Consumer Affairs, Vol. 43 No. 2, pp. 199-222.

Akaka, M.A. and Chandler, J.D. (2011), "Roles as resources: a social roles perspective of change in value networks", Marketing Theory, Vol. 11 No. 3, pp. 243-260.

Anderson, L. (2009), "Socio-culturally embedded literacies in an emerging economy", in Samu, S., Raidyanathan, R. and Chakravarti, D. (Eds), Asia-Pacific Advances in Consumer Research, Vol. 8, Association for Consumer Research, Duluth, MN, p. 30. 
Anderson, L., Ostrom, A.L., Corus, C., Fisk, R.P., Gallan, A. S., Giraldo, M., Mende, M., Mulder, M., Rayburn, S.W., Rosenbaum, M.S. and Shirahada, K. (2013), "Transformative service research: an agenda for the future", Fournal of Business Research, Vol. 66 No. 8, pp. 1203-1210.

Anderson, L., Spanjol, J., Jefferies, J.G., Ostrom, A.L., Nations Baker, C., Bone, S.A., Downey, H., Mende, M. and Rapp, J. M. (2016), "Responsibility and well-being: resource integration under responsibilization in expert services", Fournal of Public Policy \& Marketing, Vol. 35 No. 2, pp. 262-279.

Batterham, R.W., Hawkins, M., Collins, P.A., Buchbinder, R. and Osborne, R.H. (2016), "Health literacy: applying current concepts to improve health services and reduce health inequalities", Public Health, Vol. 132, pp. 3-12.

Black, H.G. and Gallan, A.S. (2015), "Transformative service networks: cocreated value as well-being", The Service Industries fournal, Vol. 35 Nos 15/16, pp. 826-845.

Blocker, C.P. and Barrios, A. (2015), "The transformative value of a service experience", Fournal of Service Research, Vol. 18 No. 3, pp. 265-283.

Brozovic, D., Ravald, A. and Nordin, F. (2015), "Making sense of service dynamics: the honeybee metaphor", fournal of Services Marketing, Vol. 29 Nos 6/7, pp. 634-644.

Callero, P.L. (1994), "From role-paying to role-using: understanding role as resource", Social Psychology Quarterly, Vol. 57 No. 3, pp. 228-243.

Cheung, L. and McColl-Kennedy, J.R. (2015), "Resource integration in liminal periods: transitioning to transformative service”, Fournal of Services Marketing, Vol. 29 Nos 6/7, pp. 485-497.

Chinn, D. (2011), "Critical health literacy: a review and critical analysis”, Social Science E Medicine, Vol. 73, pp. 60-67.

Chinn, D. and McCarthy, C. (2013), "All aspects of health literacy scale (AAHLS): developing a tool to measure functional, communicative and critical health literacy in primary healthcare settings", Patient Education and Counseling, Vol. 90 No. 2, pp. 247-253.

Creswell, J.W., Hanson, W.E., Clark Plano, V.L. and Morales, A. (2007), "Qualitative research designs: selection and implementation", The Counseling Psychologist, Vol. 35 No. 2, pp. 236-264.

Dong, B., Sivakumar, K., Evans, K.R. and Zou, S. (2015), "Effect of customer participation on service outcomes: the moderating role of participation readiness", fournal of Service Research, Vol. 18 No. 2, pp. 160-176.

Dubois, A. and Gadde, L.-E. (2014), "Systematic combining A decade later", Fournal of Business Research, Vol. 67 No. 6, pp. 1277-1284.

Edvardsson, B., Kleinaltenkamp, M., Tronvoll, B., McHugh, P. and Windahl, C. (2014), "Institutional logics matter when coordinating resource integration", Marketing Theory, Vol. 14 No. 3, pp. 291-309.

Elg, M., Engström, J., Witell, L. and Poksinska, B. (2012), "Co-creation and learning in health-care service development”, fournal of Service Management, Vol. 23 No. 3, pp. 328-343.

Elwyn, G., Frosch, D., Thomson, R., Joseph-Williams, N., Lloyd, A., Kinnersley, P., Cording, E., Tomson, D., Dodd, C., Rollnick, S., Edwards, A. and Barry, M. (2012), "Shared decision making: a model for clinical practice", fournal of General Internal Medicine, Vol. 27 No. 10, pp. 1361-1367.

Fox, N. and Ward, K. (2006), "Health identities: from expert patient to resisting consumer", Health (London, England: 1997), Vol. 10 No. 4, pp. 461-479.

Frow, P., McColl-Kennedy, J.R. and Payne, A. (2016), "Cocreation practices: their role in shaping a health care ecosystem", Industrial Marketing Management, Vol. 56, pp. 24-39.

Gallan, A.S., McColl-Kennedy, J.R., Barakshina, T., Figueiredo, B., Jefferies, J.G., Gollnhofer, J., Hibbert, S., Luca, N., Roy, S., Spanjol, J. and Winklhofer, H. (2018), "Transforming community well-being through patients' lived experiences", fournal of Business Research, pp. 1-16.

Giddens, A. (1984), The Constitution of Society: outline of the Theory of Structuration, University of CA Press, Berkley, CA.

Giesler, M. and Veresiu, E. (2014), "Creating the responsible consumer: moralistic governance regimes and consumer subjectivity", fournal of Consumer Research, Vol. 41 No. 3, pp. 840-857.

Gonçalves, S.M., da Silva, R.V. and Teixeira, N. (2018), "Individual actors and embeddedness in business-to-business interactions", Industrial Marketing Management, available at: https://doi.org/10.1016/j.indmarman.2018.08.006

Grönroos, C. (2011), "Value co-creation in service logic: a critical analysis", Marketing Theory, Vol. 11 No. 3, pp. 279-301.

Grönroos, C. and Gummerus, J. (2014), "The service revolution and its marketing implications: service logic vs service-dominant logic", Managing Service Quality: An International fournal, Vol. 24 No. 3, pp. 206-229.

Grönroos, C. and Ravald, A. (2011), "Service as business logic: implications for value creation and marketing", fournal of Service Management, Vol. 22 No. 1, pp. 5-22.

Gummesson, E. and Mele, C. (2010), "Marketing as value cocreation through network interaction and resource integration", Fournal of Business Market Management, Vol. 4 No. 4, pp. 181-198.

Heinonen, K. (2018), "Positive and negative valence influencing consumer engagement", fournal of Service Theory and Practice, Vol. 28 No. 2, pp. 147-169.

Helkkula, A., Kelleher, C. and Pihlström, M. (2012), "Characterizing value as an experience: implications for service researchers and managers", fournal of Service Research, Vol. 15 No. 1, pp. 59-75.

Hibbard, J.H. and Greene, J. (2013), "What the evidence shows about patient activation: better health outcomes and care experiences; fewer data on costs", Health Affairs, Vol. 32 No. 2, pp. 207-214.

Holt, D.B. (1995), "How consumers consume: a typology of consumption practices", fournal of Consumer Research, Vol. 22 No. 1, pp. 1-16.

Huber, J. and Skidmore, P. (2003), The New, old: Why Baby Boomers Won't be Pensioned Off, Demos, London.

Jones, L. (2010), "Introduction: challenge and controversy in promoting public health", in J. Douglas, J., Earle, S., Handsley, S., Jones, L., Lloyd, C.E. and Spurr, S. (Eds), $A$ Reader in Promoting Public Health, 2nd ed., Sage, London, pp. 1-3. 
Kasnakoglu, B.T. (2016), "Antecedents and consequences of co-creation in credence-based service contexts", The Service Industries fournal, Vol. 36 Nos 1/2, pp. 1-20.

Keeling, D.I., Laing, A. and De Ruyter, K. (2018), "Evolving roles and structures of triadic engagement in healthcare", Fournal of Service Management, Vol. 29 No. 3, pp. 352-377.

Light, D. (2010), "Health-care professions, markets and countervailing powers”, in Bird, C.E., Conrad, P., Fremont, A.M. and Timmermans, S. (Eds), Handbook of Medical Sociology, 6th ed, Vanderbilt University Press, Nashville, TN, pp. 270-289.

Lusch, R.F., Vargo, S.L. and Tanniru, M. (2010), "Service, value networks and learning", fournal of the Academy of Marketing Science, Vol. 38 No. 1, pp. 19-31.

Lynch, K.D. (2007), "Modeling role enactment: linking role theory and social cognition", fournal for the Theory of Social Behaviour, Vol. 37 No. 4, pp. 379-399.

McColl-Kennedy, J.R., Snyder, H., Elg, M., Witell, L., Helkkula, A., Hogan, S.J. and Anderson, L. (2017), “The changing role of the health care customer: review, synthesis and research agenda", fournal of Service Management, Vol. 28 No. 1, pp. 2-33.

McColl-Kennedy, J.R., Vargo, S.L., Dagger, T.S., Sweeney, J. C. and van Kasteren, Y. (2012), "Health care customer value cocreation practice styles", fournal of Service Research, Vol. 15 No. 4, pp. 370-389.

Martin, P.Y. and Turner, B.A. (1986), "Grounded theory and organizational research", The fournal of Applied Behavioral Science, Vol. 22 No. 2, pp. 141-157.

Mele, C., Spena, T.R. and Colurcio, M. (2010), "Co-creating value innovation through resource integration", International Fournal of Quality and Service Sciences, Vol. 2 No. 1, pp. 60-78.

Mende, M., Scott, M.L., Bitner, M.J. and Ostrom, A.L. (2017), "Activating consumers for better service coproduction outcomes through eustress: the interplay of firm-assigned workload, service literacy, and organizational support”, Fournal of Public Policy \& Marketing, Vol. 36 No. 1, pp. 137-155.

Meuter, M.L., Bitner, M.J., Ostrom, A.L. and Brown, S.W. (2005), "Choosing among alternative service delivery modes: an investigation of customer trial of self-service technologies", Fournal of Marketing, Vol. 69 No. 2, pp. 61-83.

Miles, M. and Huberman, A.M. (1994), Qualitative Data Analysis: An Expanded Sourcebook, 2nd ed., Sage, Thousand Oaks, CA.

Moeller, S., Ciuchita, R., Mahr, D., Odekerken-Schröder, G. and Fassnacht, M. (2013), "Uncovering collaborative value creation patterns and establishing corresponding customer roles", Fournal of Service Research, Vol. 16 No. 4, pp. 471-487.

Mol, A. (2008), The Logic of Care: health and the Problem of Patient Choice, Routledge, Milton Park.

Noble, S.M., Schewe, C.D. and Kuhr, M. (2004), "Preferences in health care service and treatment: a generational perspective", fournal of Business Research, Vol. 57 No. 9, pp. 1033-1041.
Nutbeam, D. (2000), "Health literacy as a public health goal: a challenge for contemporary health education and communication strategies into the 21 st century", Health Promotion International, Vol. 15 No. 3, pp. 259-267.

Osborne, R.H., Batterham, R.W., Elsworth, G.R., Hawkins, M. and Buchbinder, R. (2013), "The grounded psychometric development and initial validation of the health literacy questionnaire (HLQ)", BMC Public Health, Vol. 13 No. 1, pp. 658-675.

Ownby, R.L., Acevedo, A., Waldrop-Valverde, D., Jacobs, R.J. and Caballero, J. (2014), "Abilities, skills and knowledge in measures of health literacy", Patient Education and Counseling, Vol. 95 No. 2, pp. 211-217.

Patton, M.Q. (2002), Qualitative Research and Evaluation Methods, 3rd ed., Sage Publications, Thousand Oaks, CA.

Payne, A., Storbacka, K. and Frow, P. (2008), "Managing the co-creation of value", fournal of the Academy of Marketing Science, Vol. 36 No. 1, pp. 83-96.

Petersen, A. and Lupton, D. (1996), The New Public Health: Health and Self in the Age of Risk, Sage, London.

Phillipson, C., Leach, R., Money, A. and Biggs, S. (2008), "Social and cultural constructions of ageing: the case of the baby boomers", Sociological Research Online, Vol. 13 No. 3, pp. 1-14.

Plé, L. and Chumpitaz-Cáceres, R. (2010), "Not always cocreation: introducing interactional co-destruction of value in service-dominant logic", Fournal of Services Marketing, Vol. 24 No. 6, pp. 430-437.

Prahalad, C.K. and Ramaswamy, V. (2004), "Co-creation experiences: the next practice in value creation", fournal of Interactive Marketing, Vol. 18 No. 3, pp. 5-14.

Quine, S. and Carter, S. (2006), “Australian baby boomers' expectations and plans for their old age", Australasian fournal on Ageing, Vol. 25 No. 1, pp. 3-8.

Ricoeur, P. (1976), Interpretation Theory: Discourse and the Surplus of Meaning, TCU Press, Fort Worth, TX.

Rosenbaum, M. (2015), "Transformative service research: research that matters", Service Industries fournal, Vol. 35 Nos 15/16, pp. 801-805.

Russell-Bennett, R., Wood, M. and Previte, J. (2013), "Fresh ideas: services thinking for social marketing", Fournal of Social Marketing, Vol. 3 No. 3, pp. 223-238.

Schneider, C.E. and Hall, M.A. (2009), "Patient life: can consumers direct health care?", American Fournal of Law $\mathcal{G}$ Medicine, Vol. 35 No. 1, pp. 7-65.

Schulz, P.J. and Nakamoto, K. (2012), "Health literacy and patient empowerment in health communication: the importance of separating conjoined twins", Patient Education and Counseling, Vol. 90 No. 1, pp. 4-11.

Sewell, W.H. Jr, (1992), "A theory of structure: duality, agency, and transformation", American fournal of Sociology, Vol. 98 No. 1, pp. 1-29.

Solomon, M.R., Surprenant, C. and Czepiel, J.A. (1985), "A role theory perspective on dyadic interactions: the service encounter", fournal of Marketing, Vol. 49 No. 1, pp. 99-111.

Sørensen, K., Van den Broucke, S., Fullam, J., Doyle, G., Pelikan, J., Slonska, Z. and Brand, H. (2012), "Health literacy and public health: a systematic review and integration of definitions and models", BMC Public Health, Vol. 12 No. 1, pp. 80-93. 
Sweeney, J.C., Danaher, T.S. and McColl-Kennedy, J.R. (2015), "Customer effort in value co-creation activities: improving quality of life and behavioral intentions of health care customers", fournal of Service Research, Vol. 18 No. 3, pp. 318-335.

Thorne, S., Oliffe, J.L. and Stajduhar, K.I. (2013), "Communicating shared decision-making: cancer patient perspectives", Patient Education and Counseling, Vol. 90 No. 3, pp. 291-296.

Tommasetti, A., Troisi, O. and Vesci, M. (2017), "Measuring customer value co-creation behavior: developing a conceptual model based on service-dominant logic", fournal of Service Theory and Practice, Vol. 27 No. 5, pp. 930-950.

Vafeas, M., Hughes, T. and Hilton, T. (2016), "Antecedents to value diminution", a Dyadic Perspective, Marketing Theory, Vol. 16 No. 4, pp. 469-491.

Vargo, S.L. and Lusch, R.F. (2004), "Evolving to a new dominant logic for marketing", fournal of Marketing, Vol. 68 No. 1, pp. 1-17.

Vargo, S.L. and Lusch, R.F. (2008), "Service-dominant logic: continuing the evolution", Fournal of the Academy of Marketing Science, Vol. 36 No. 1, pp. 1-10.

Vargo, S.L. and Lusch, R.F. (2016), "Institutions and axioms: an extension and update of service-dominant logic", fournal of the Academy of Marketing Science, Vol. 44 No. 1, pp. 5-23.

Verleye, K. (2015), "The co-creation experience from the customer perspective: its measurement and determinants", Fournal of Service Management, Vol. 26 No. 2, pp. 321-342.

Verleye, K., Gemmel, P. and Rangarajan, D. (2014), "Managing engagement behaviors in a network of customers and stakeholders: evidence from the nursing home sector", Fournal of Service Research, Vol. 17 No. 1, pp. 68-84.

Weick, K.E. (1995), Sensemaking in Organizations, Sage, Newbury Park, CA.

World Health Organisation WHO (2010), "Gender, women and primary health care renewal", A discussion paper, WHO, Geneva.

\section{Further reading}

McColl-Kennedy, J.R., Cheung, L. and Ferrier, E. (2015), "Co-creating service experience practices", fournal of Service Management, Vol. 26 No. 2, pp. 249-275.

\section{Corresponding author}

Janet Davey can be contacted at: janet.davey@vuw.ac.nz

For instructions on how to order reprints of this article, please visit our website: 